\title{
Measuring Attitude Towards Chemistry, Biology, and Math at a Hispanic-Serving Institution
}

Jordan Chang and Erik Menke

Department of Chemistry and Biochemistry, University of California, Merced

Merced, CA 95343, United States

\begin{abstract}
This work describes the evaluation of the Attitude toward the Subject of Chemistry Inventory (ASCI), as well as two modifications (one for measuring attitude toward math and one for measuring attitude toward biology), for college students at a Hispanic Serving Institution. Instrument reliability was tested via multiple administrations of the instruments, and confirmatory factor analysis supported a two-factor structure similar to an existing model of a revised version of the ASCI for all three instruments. The similar factor structure of the three instruments, coupled with interviews with students, provide validity evidence for the instruments and support an interpretation that one of the subscales aligns with a cognitive aspect of attitude while the other subscale aligns with an affective aspect. The results of these instruments indicate that students have a more positive attitude towards biology than either chemistry or math, and more positive affective attitude than cognitive attitude for all three subjects, although student attitudes show little change with respect to biology, chemistry, or math during a typical semester. However, major perturbations, such as switching to remote instruction mid-semester, can lead to small but significant increases and decreases in attitude.
\end{abstract}

\section{Introduction}

What is attitude? While attitude can have a variety of context-dependent definitions, psychologists generally hold that attitude is a multidimensional construct that depends on knowledge, feeling, and behavior, and must be directed at something or someone in either a positive or negative manner. More formally, attitude is a tripartite structure that combines 1) a cognitive dimension (knowledge), 2) an affective dimension (feeling), and 3) an action dimension (behavior) ${ }^{1-4}$ This tripartite structure can lead to similar attitudes about something, but for different reasons. As an example, consider two biology graduate students, one who is deeply knowledgeable about protein structure and enjoys solving crystal structures, but is squeamish about dissecting animals, and another who feels very confident working in a lab and is unfazed by the sight of blood, but worries about her depth of knowledge and finds exams stressful. Both students likely have a positive attitude towards biology, otherwise they probably wouldn't be in graduate school studying biology, but for different underlying reasons.

An important reason for understanding attitude is that attitude has been shown to affect behavior. For example, a student who finds chemistry engaging, likes thinking about chemistry problems, and feels confident while carrying out chemistry experiments is more likely to continue taking chemistry courses, or even major in chemistry, than a student who finds chemistry frustrating, dislikes thinking about chemistry problems, and feels clumsy when carrying out chemistry experiments. A generally accepted model linking attitude with behavior is Theory of Planned Behavior, ${ }^{5}$ developed by Ajzen in the 1980's as an extension of Ajzen and Fishbein's Theory of Reasoned Action. ${ }^{6-8}$ The Theory of Planned Behavior posits that 1) attitude towards a behavior, 2) subjective norms, and 3) perceived behavior control all modulate a person's intention to behave, which then impacts their actual behavior. Of these three inputs, attitude towards a behavior is the most important. This model has been shown to be effective for 
understanding the relationship between student attitude and behavior in physics. ${ }^{9-10}$ More broadly, fostering positive student attitudes toward science has been shown to correlate strongly with student achievement, persistence, and retention. ${ }^{11-26}$

An important result of this idea that attitude modulates behavior is that if we want to improve student success in science, we must improve student attitudes about science. It's well known that undergraduate students leave STEM majors at a high rate, ${ }^{27}$ and this rate is even higher for students from historically underrepresented groups (African American, Hispanic, Native American, etc.), with the disparity increasing at higher degree levels. ${ }^{28-29}$ While student-centered teaching methods have been shown to increase retention and learning, and even narrow the retention gap, ${ }^{30-35}$ much of this research has occurred at large, relatively wealthy and primarily white research institutions, and it's not always clear that the lessons translate to institutions with more diverse populations, like community colleges, historically Black colleges and universities (HBCUs) or Hispanic-serving institutions (HSIs). ${ }^{36-39}$

While nearly all faculty likely feel competent to assess student skills and knowledge in a particular subject, assessing attitude is often viewed as much more difficult, in part due to their lack of knowledge about attitude. This is compounded by the difficulty that attitude cannot be measured directly but must be inferred. For this reason, a few instruments for measuring attitude in science classrooms and towards science subjects have been developed. ${ }^{11,40-49}$ One of these measures is the Attitude toward the Subject of Chemistry Inventory (ASCI), developed by Bauer. $^{42}$ While the ASCI showed promise and was used to measure attitude towards chemistry for a number of studies there was some concern about interpretation of the instrument as well as how applicable it was to various populations. To address these concerns $\mathrm{Xu}$ and Lewis refined the ASCI to make it easier to interpret and to better measure attitude towards chemistry for a wider range of student populations, as well as a second refinement altering the item order to improve the instrument's factor structure. ${ }^{11,15}$

\section{Research questions}

As part of a 5-year goal for the chemistry department to implement and assess pedagogical changes in the lower-division chemistry courses, we were interested in measuring student attitude to track the impact of interventions. In addition, several initiatives across the school aimed at improving lower division science courses are either being planned or have recently been introduced. For example, we are currently piloting a learning assistant program in chemistry, biology, math, and physics. There has also been discussion among chemistry and biology faculty about ways to introduce culturally relevant science teaching practices. Most of these changes are motivated by the rather unique student population we serve. Table 1 shows the campus demographics from the past few years. Because many of the curricular changes we are planning are aimed at both improving student learning and student feeling of belonging, we wanted a way to reliable measure changes in student attitude towards a variety of sciences.

Table 1. Campus undergraduate student demographics and Pell grant recipients, by year

\begin{tabular}{|l|r|r|r|r|r|}
\hline & 2016 & 2017 & 2018 & 2019 & 2020 \\
\hline African American & $6.46 \%$ & $6.56 \%$ & $6.60 \%$ & $6.58 \%$ & $7.02 \%$ \\
\hline American Indian & $0.48 \%$ & $0.42 \%$ & $0.38 \%$ & $0.33 \%$ & $0.39 \%$ \\
\hline Asian & $23.87 \%$ & $22.36 \%$ & $21.57 \%$ & $21.09 \%$ & $19.71 \%$ \\
\hline Hispanic/Latino(a) & $49.71 \%$ & $51.59 \%$ & $52.72 \%$ & $53.86 \%$ & $55.76 \%$ \\
\hline
\end{tabular}




\begin{tabular}{|l|r|r|r|r|r|} 
White & $11.23 \%$ & $10.14 \%$ & $9.57 \%$ & $8.81 \%$ & $8.02 \%$ \\
\hline $\begin{array}{l}\text { Domestic } \\
\text { Unknown }\end{array}$ & $1.60 \%$ & $1.52 \%$ & $1.50 \%$ & $1.50 \%$ & $1.55 \%$ \\
\hline International & $6.65 \%$ & $7.40 \%$ & $7.66 \%$ & $7.84 \%$ & $7.55 \%$ \\
\hline Pell grant recipients & $60.66 \%$ & $63.92 \%$ & $63.93 \%$ & $63.62 \%$ & $62.76 \%$ \\
\hline
\end{tabular}

While we planned on using one of the ASCI variants there were two issues that concerned us. First, while the ASCI V2 and ASCI V3 had been shown to reliably measure attitude towards chemistry for a variety of undergraduate populations, ${ }^{15,18-19}$ in part because there are cultural differences to how the questions are interpreted, ${ }^{50}$ leading to some concerns about the validity of the instruments for our institution. Furthermore, it was unclear that either instrument had been administered at a Hispanic-Serving Institution (defined as an institution of higher education with an undergraduate population of at least 25\% Hispanic students), and issues with ASCI V2 arose when used to measure students attitudes towards chemistry in Chile. ${ }^{51}$

Second, given the proposed changes to a variety of programs, we were interested in measuring student attitudes not just towards chemistry, but comparing student attitudes in chemistry, biology, and math, and we were unaware of any instrument that provided this capability. Therefore, the focus of this study was to investigate how to measure student attitudes reliably, understand how attitude might vary over the course of a semester, and gauge how student attitudes might differ based on subject. With this in mind, three questions guided our work:

1. Can students' attitudes about chemistry, biology, and math at a Hispanic-Serving Institution be measured using the same instrument and similar methods as at a nonminority institution?

2. Do student's attitudes about chemistry, biology, and math change over the course of a typical semester?

3. How similar are students' attitudes for chemistry, biology, and math?

\section{Methods}

All work involving human subjects was approved by UC Merced's Institutional Review Board (study \#UCM2018-102). The only exclusion criteria was age (students under 18 were excluded) due to the difficulty associated with requesting parental consent coupled with the low likelihood of having potential participants under 18. No incentives were provided to students to participate in this work, and no demographic or other identifying information was collected as part of this study.

For the first three semesters of this project (Spring 2019, Fall 2019, and Spring 2020), the original Attitude toward the Subject of Chemistry Inventory (ASCI V1), as well as two modified versions of the ASCI V1, were administered twice per semester. One of the modified inventories consisted of changing the survey prompt from "Chemistry is" to "Biology is", while the other modified inventory had the prompt changed to "Math is", in an effort to measure student attitudes towards chemistry, math, and biology, based on prior work by Wachsmuth et al. modifying the ASCI V2 to measure attitudes towards math held by biology students. ${ }^{46}$ All three inventories were combined into a single survey (see SI) and given electronically via Qualtrics. Starting in the fourth semester of this project (Fall 2020), based on the analysis below, we started 
administering the revised version of the inventory. This revised version (see SI) is a shortened version of the three inventories above, with 6 pairs of adjectives organized into 2 subscales for each subject (chemistry, biology, and math). This administration of the survey also included a question asking the students to identify what chemistry class they were currently taking.

For each administration, the instruments were distributed via email as a single Qualtrics survey to students in the Preparatory Chemistry, first-semester General Chemistry, secondsemester General Chemistry, and first-semester Organic Chemistry courses at a western public research university that is also a Hispanic serving institution (HSI). The survey was distributed twice per semester, once during the first week of instruction ("presemester") and once during the final week of instruction ("postsemester"). For the students in the Preparatory Chemistry and General Chemistry courses, time was allotted during the first discussion session for the students to take the presemester survey during the discussion on their own computers. Due to time limitations for these courses there was no time set aside for the postsemester survey, so the students were asked to take the survey on their own time. Additionally, the Organic Chemistry course did not have discussion sections, and so students were asked to take both the presemester and postsemester surveys on their own time. Response rates, shown in Table 2, ranged from a high of $59 \%$ to a low of $10 \%$, with the postsemester rates lower than the presemester rates, likely due to the in-class time provided for the presemester surveys.

Survey responses from students who did not consent to participate were not included in the analysis. In addition, any surveys with only one or two instruments completed were also not included in the analysis. Finally, any responses with missing data were excluded from analysis. The missing data was checked to determine if it might bias the findings, but no evidence of bias was found.

Each administration of the instruments was analyzed for evidence of reliability and validity. Descriptive statistics were performed in Python using the pingouin package for all items after the negatively stated items were recoded. To allow for comparison with other work, the 7-point Likert scale for each instrument was converted to a percentage, as per Bauer's original paper. Skewness and kurtosis of the data was less than $|1|$ for most, and less than $|2|$ for all, of the data, revealing good normality of item scores (SI tables 1 through 24). Differences in factor scores were quantified by Cohen's $d$ effect size, using common guidelines $(d>0.2$ is a small effect, $d>$ 0.5 is a medium effect, and $d>0.8$ is a large effect). ${ }^{52}$

Confirmatory factor analysis (CFA) was used to confirm three different models: 1) the fourfactor model proposed by Bauer, 2) the two-factor model proposed by $\mathrm{Xu}$ and Lewis and 3) a modified two-factor model. CFA was performed in R using the lavaan package. To allow for comparison with prior work, similar CFA methods, fit measures and evaluation criteria were used. Specifically, CFA was performed using the variance-covariance matrix with a maximumlikelihood method of estimation. All items were set to load on their assumed factors, and $\chi^{2}$, comparative fit index (CFI) and standardized root-mean-squared residual (SRMR) values were calculated, and a model was rejected if the CFI was below 0.9 or the SRMR was above 0.08.

Finally, in an effort to better understand the revised instrument, 9 undergraduate students who took the presemester survey in during the Fall, 2021, semester were interviewed about the survey. The interviews were semistructured (the interview script is provided in the SI), focusing on the how the students interpreted the surveys and potential issues they observed. These surveys were carried out via Zoom, and the audio was transcribed via a Zoom cloud service. These 
transcribed documents were then analyzed by the corresponding author. All students have been assigned a pseudonym for the purposes of quotes.

\section{Results and discussion}

\section{Factor analysis}

Consistent with prior work by $\mathrm{Xu}$ and Lewis, the results from the CFA indicated that, for our population, the data does not support the four-factor model proposed by Bauer. ${ }^{11}$ Furthermore, the CFA results indicated that, for our population, the data only sometimes supports the twofactor model proposed by Xu and Lewis. Specifically, while the CFI and SRMR thresholds were usually met for both the chemistry and math attitude surveys, they were not met for the biology attitude survey. Analysis of the factor loadings and residual variances (SI tables 25 and 26) indicated that item 10 (challenging/not challenging) and item 17 (chaotic/organized) only weakly contribute to the intellectual accessibility and emotional satisfaction factors, respectively. Interestingly, item 10 has also been shown to have high variance and poor loading for a sample of Saudi Arabian students, suggesting that the challenging/not challenging item is problematic for students from a variety of cultures. ${ }^{50}$ Therefore, we tested an alternative two-factor model with these items removed. CFA results for this alternative model indicated that, for our population, the data always supports this revised two-factor model, except for the Spring, 2019, biology postsemester survey. Table 2 compares the results of the CFA for both models. These results stand in contrast to prior work on developing the Attitude toward the Subject of Mathematics Inventory, where exploratory factor analysis on the ASCI V2, modified to measure attitudes of math among biology students, didn't neatly resolve into two factors, in part because of issues with item $10,{ }^{46}$ as well as a prior attempt to modify the ASCI V3 to measure attitude towards calculus. ${ }^{53} \mathrm{We}$ also note that internal consistencies, measured by Cronbach's $\alpha$ for proposed subscales, where $\alpha 1$ is the Cronbach's alpha for the first subscale and $\alpha 2$ is the Cronbach's alpha for the second subscale, are between 0.73 and 0.92 and similar between the two models.

Table 2: Number of responses, response rates, Cronbach's alpha, chi-square, comparison fit index, and standardized root-mean-square residual values for the original two-factor model and revised two-factor model for pre and post semester surveys administered during the Spring, 2019, Fall, 2019, Spring, 2020, and Fall, 2020, surveys

\begin{tabular}{|c|c|c|c|c|c|c|c|c|c|c|c|c|}
\hline \multirow{2}{*}{$\begin{array}{c}\text { Semeste } \\
\mathrm{r}\end{array}$} & \multirow{2}{*}{ Survey } & \multirow{2}{*}{$\mathrm{N}(\%)$} & \multicolumn{5}{|c|}{$\mathrm{Xu}$ and Lewis model } & \multicolumn{5}{|c|}{ Revised two-factor model } \\
\hline & & & $\alpha 1$ & $\alpha 2$ & $\chi^{2}$ & CFI & SRMR & $\alpha 1$ & $\alpha 2$ & $\chi^{2}$ & CFI & SRMR \\
\hline \multirow{6}{*}{$\begin{array}{c}2019 \\
\text { Spring }\end{array}$} & $\begin{array}{l}\text { Biology } \\
\text { pre }\end{array}$ & $\begin{array}{c}685 \\
(59 \%) \\
\end{array}$ & 0.78 & 0.75 & 171.0 & 0.885 & 0.094 & 0.77 & 0.80 & 72.3 & 0.940 & 0.066 \\
\hline & $\begin{array}{l}\text { Chemistr } \\
\text { y pre }\end{array}$ & $\begin{array}{c}685 \\
(59 \%) \\
\end{array}$ & 0.78 & 0.75 & 131.0 & 0.928 & 0.062 & 0.77 & 0.79 & 49.6 & 0.967 & 0.046 \\
\hline & Math pre & $\begin{array}{c}685 \\
(59 \%)\end{array}$ & 0.83 & 0.82 & 216.1 & 0.912 & 0.077 & 0.82 & 0.85 & 95.8 & 0.950 & 0.053 \\
\hline & $\begin{array}{l}\text { Biology } \\
\text { post }\end{array}$ & $\begin{array}{c}174 \\
(15 \%)\end{array}$ & 0.82 & 0.80 & 104.4 & 0.854 & 0.131 & 0.78 & 0.88 & 38.8 & 0.931 & 0.087 \\
\hline & $\begin{array}{l}\text { Chemistr } \\
\text { y post }\end{array}$ & $\begin{array}{c}174 \\
(15 \%)\end{array}$ & 0.82 & 0.81 & 64.4 & 0.919 & 0.061 & 0.81 & 0.84 & 30.9 & 0.951 & 0.056 \\
\hline & $\begin{array}{l}\text { Math } \\
\text { post }\end{array}$ & $\begin{array}{c}174 \\
(15 \%)\end{array}$ & 0.87 & 0.83 & 54.8 & 0.944 & 0.055 & 0.87 & 0.87 & 17.9 & 0.979 & 0.038 \\
\hline \multirow{2}{*}{$\begin{array}{r}2019 \\
\text { Fall }\end{array}$} & $\begin{array}{l}\text { Biology } \\
\text { pre }\end{array}$ & $\begin{array}{c}389 \\
(24 \%)\end{array}$ & 0.74 & 0.78 & 143.3 & 0.863 & 0.104 & 0.73 & 0.83 & 50.0 & 0.945 & 0.066 \\
\hline & $\begin{array}{l}\text { Chemistr } \\
\text { y pre }\end{array}$ & $\begin{array}{c}389 \\
(24 \%)\end{array}$ & 0.80 & 0.80 & 105.5 & 0.928 & 0.067 & 0.81 & 0.84 & 54.0 & 0.952 & 0.055 \\
\hline
\end{tabular}




\begin{tabular}{|c|c|c|c|c|c|c|c|c|c|c|c|c|}
\hline & Math pre & $\begin{array}{c}389 \\
(24 \%)\end{array}$ & 0.80 & 0.79 & 110.7 & 0.917 & 0.069 & 0.81 & 0.84 & 55.4 & 0.945 & 0.059 \\
\hline & $\begin{array}{l}\text { Biology } \\
\text { post }\end{array}$ & $\begin{array}{c}203 \\
(13 \%) \\
\end{array}$ & 0.84 & 0.82 & 43.0 & 0.949 & 0.070 & 0.85 & 0.85 & 16.7 & 0.977 & 0.048 \\
\hline & $\begin{array}{l}\text { Chemistr } \\
\text { y post }\end{array}$ & $\begin{array}{c}203 \\
(13 \%) \\
\end{array}$ & 0.78 & 0.80 & 70.0 & 0.909 & 0.082 & 0.77 & 0.82 & 47.5 & 0.919 & 0.075 \\
\hline & $\begin{array}{l}\text { Math } \\
\text { post }\end{array}$ & $\begin{array}{c}203 \\
(13 \%)\end{array}$ & 0.86 & 0.81 & 38.2 & 0.970 & 0.050 & 0.85 & 0.85 & 15.1 & 0.987 & 0.033 \\
\hline \multirow{6}{*}{$\begin{array}{c}2020 \\
\text { Spring }\end{array}$} & $\begin{array}{l}\text { Biology } \\
\text { pre }\end{array}$ & $\begin{array}{c}305 \\
(26 \%) \\
\end{array}$ & 0.78 & 0.76 & 83.7 & 0.882 & 0.105 & 0.74 & 0.82 & 41.5 & 0.930 & 0.080 \\
\hline & $\begin{array}{l}\text { Chemistr } \\
\text { y pre }\end{array}$ & $\begin{array}{c}305 \\
(26 \%)\end{array}$ & 0.79 & 0.76 & 91.1 & 0.907 & 0.082 & 0.79 & 0.81 & 37.6 & 0.950 & 0.066 \\
\hline & Math pre & $\begin{array}{c}305 \\
(26 \%)\end{array}$ & 0.83 & 0.79 & 91.7 & 0.927 & 0.074 & 0.82 & 0.84 & 38.5 & 0.960 & 0.057 \\
\hline & $\begin{array}{l}\text { Biology } \\
\text { post }\end{array}$ & $\begin{array}{c}111 \\
(10 \%) \\
\end{array}$ & 0.85 & 0.79 & 73.6 & 0.862 & 0.100 & 0.87 & 0.82 & 37.1 & 0.916 & 0.080 \\
\hline & $\begin{array}{l}\text { Chemistr } \\
\text { y post }\end{array}$ & $\begin{array}{c}111 \\
(10 \%)\end{array}$ & 0.79 & 0.77 & 44.5 & 0.920 & 0.087 & 0.74 & 0.86 & 14.5 & 0.975 & 0.052 \\
\hline & $\begin{array}{l}\text { Math } \\
\text { post }\end{array}$ & $\begin{array}{c}111 \\
(10 \%)\end{array}$ & 0.84 & 0.83 & 80.3 & 0.868 & 0.090 & 0.84 & 0.86 & 16.7 & 0.972 & 0.049 \\
\hline \multirow{6}{*}{$\begin{array}{l}2020 \\
\text { Fall }\end{array}$} & $\begin{array}{l}\text { Biology } \\
\text { pre }\end{array}$ & $\begin{array}{c}551 \\
(37 \%) \\
\end{array}$ & & & & & & 0.82 & 0.88 & 83.9 & 0.934 & 0.069 \\
\hline & $\begin{array}{l}\text { Chemistr } \\
\text { y pre }\end{array}$ & $\begin{array}{c}551 \\
(37 \%) \\
\end{array}$ & & & & & & 0.80 & 0.85 & 44.0 & 0.970 & 0.044 \\
\hline & Math pre & $\begin{array}{c}551 \\
(37 \%) \\
\end{array}$ & & & & & & 0.84 & 0.89 & 126.2 & 0.926 & 0.080 \\
\hline & $\begin{array}{l}\text { Biology } \\
\text { post }\end{array}$ & $\begin{array}{c}260 \\
(18 \%) \\
\end{array}$ & & & & & & 0.85 & 0.92 & 66.9 & 0.944 & 0.069 \\
\hline & $\begin{array}{l}\text { Chemistr } \\
\text { y post }\end{array}$ & $\begin{array}{c}260 \\
(18 \%) \\
\end{array}$ & & & & & & 0.82 & 0.85 & 49.4 & 0.936 & 0.078 \\
\hline & $\begin{array}{l}\text { Math } \\
\text { post }\end{array}$ & $\begin{array}{c}260 \\
(18 \%) \\
\end{array}$ & & & & & & 0.86 & 0.89 & 45.7 & 0.947 & 0.057 \\
\hline
\end{tabular}

Based on the CFA results, we wanted to test a modified version of the instruments that only consisted of the six items (easy/hard, complicated/simple, confusing/clear, comfortable/uncomfortable, satisfying/frustrating, and pleasant/unpleasant) that factored reliably using our new 2-factor model. These updated instruments were distributed during the Fall, 2020, semester, and show similar $\chi^{2}$, CFI, and SRMR values as the ASCI V2 with this model, as well as similar factor loadings and residual variances (SI tables 27 and 28). This all suggests that these three instruments are reliably measuring something, although not necessarily attitude.

\section{Student interviews}

The analysis above provides statistical evidence for combining the items into 2 subscales for each instrument. However, just because these instruments factor into two subscales in similar ways doesn't necessarily mean that they are measuring similar things. While the similarity of these instruments to the ASCI V2, as well as similar underlying structure, provide face validity that they are measuring attitude in similar ways, we wanted to see if students were interpreting the same item from different instruments in similar ways. For example, while students may rate easy vs. hard similarly for biology and math, the idea of pleasure in math vs biology might be very different.

To assess how students were interpreting the three instruments, we interviewed 9 different students shortly after they took the Fall, 2021, presemester survey. These interviews were held remotely via Zoom and took about 15 minutes each. The students were shown each instrument, one at a time, and asked to rate each item. They were then asked if any items seemed out of 
place, or about any difficulties they had with providing a rating. Finally, they were asked for their overall thoughts on the instruments.

During the interviews the students raised a few potential issues. Multiple students noted the difficulty of separating feelings about a subject with feelings about a teacher. Inara, for example, thought that "it's a really good idea to include the 'try not to include your feelings towards math teachers" section of the instructions because "that will definitely influence some people's perspective on the subject" while Luis suggested that "something may be complicated or easier because of the professor's explanation". David was concerned about how someone's interpretation of the scale might change over time, telling us that "what I say is a two one semester might the same as a four another semester". Also, George was concerned that there is "bias towards the [subjects] I don't have very much knowledge in and just judging the surface level about them". Finally, one of the items (satisfying to frustrating) was noted as potentially problematic by multiple students. Inara, for example, felt that "the opposite of frustrating being...something more like understandable", Luis thought that "frustrating is just meaning the same thing as complicated", and Virginia "can see how the subject can be satisfying once you get the hang of it, but I understand more frustration than satisfying".

Despite these concerns, though, the students found the survey easy to understand, approached the three different subject instruments similarly, and indicated the word pairs did a reasonable job of representing how they feel about the three subjects. For example, Virginia said that "of the three core subjects it was interesting to see ...what I enjoyed in each on", while Benicio said that the "whole survey was pretty, you know, easy to understand" and "how you feel about a particular topic... was fairly easy to gauge". George also seemed to appreciate the different feelings about a subject, noting that "some things that are complicated can be pleasant, but some things that are simple can be pleasant". Given the results of factor analysis, the similarity of the final instruments to the ASCI V2, and the interviewed students' consistent approach to the different instruments, we felt it was reasonable to treat all three subject instruments similarly and combine the items into 2 subscales identified as "Intellectual accessibility" and "Emotional satisfaction", consistent with prior work by Xu and Lewis.

\section{Survey results}

Table 3: Presemester and postsemester mean scores, reported as percentages, p-values, and effect sizes for the intellectual accessibility and emotional satisfaction scales for each subject, from the Spring, 2019, Fall, 2019, Spring 2020, and Fall, 2020 semesters.

\begin{tabular}{|l|r|r|r|r|}
\hline Spring 2019 & Presemester & Postsemester & p-value & \multicolumn{1}{l|}{$\begin{array}{l}\text { Effect } \\
\text { size }\end{array}$} \\
\hline $\begin{array}{l}\text { Intellectual } \\
\text { accessibility }\end{array}$ & & & & \\
\hline CHEM & 49.38 & 47.56 & 0.194 & -0.12 \\
\hline BIO & 53.11 & 50.68 & 0.135 & -0.13 \\
\hline MATH & 46.59 & 46.58 & 0.995 & 0.00 \\
\hline Emotional satisfaction & & & & \\
\hline CHEM & 62.94 & 60.57 & 0.123 & -0.14 \\
\hline BIO & 68.42 & 64.64 & 0.016 & -0.23 \\
\hline MATH & 61.87 & 62.21 & 0.862 & -0.02 \\
\hline & & & & \\
\hline
\end{tabular}




\begin{tabular}{|c|c|c|c|c|}
\hline Fall 2019 & Presemester & Postsemester & p-value & $\begin{array}{l}\text { Effect } \\
\text { size }\end{array}$ \\
\hline \multicolumn{5}{|l|}{$\begin{array}{l}\text { Intellectual } \\
\text { accessibility }\end{array}$} \\
\hline CHEM & 45.11 & 45.98 & 0.558 & 0.05 \\
\hline $\mathrm{BIO}$ & 52.22 & 54.07 & 0.278 & 0.10 \\
\hline MATH & 47.02 & 46.40 & 0.741 & -0.03 \\
\hline \multicolumn{5}{|c|}{ Emotional satisfaction } \\
\hline CHEM & 60.38 & 61.29 & 0.559 & 0.05 \\
\hline $\mathrm{BIO}$ & 69.00 & 66.57 & 0.105 & -0.14 \\
\hline MATH & 62.90 & 60.05 & 0.132 & -0.13 \\
\hline Spring 2020 & Presemester & Postsemester & p-value & $\begin{array}{l}\text { Effect } \\
\text { size }\end{array}$ \\
\hline \multicolumn{5}{|l|}{$\begin{array}{l}\text { Intellectual } \\
\text { accessibility }\end{array}$} \\
\hline CHEM & 44.26 & 47.45 & 0.071 & 0.20 \\
\hline $\mathrm{BIO}$ & 53.25 & 48.11 & 0.051 & -0.23 \\
\hline MATH & 45.03 & 44.62 & 0.853 & -0.02 \\
\hline \multicolumn{5}{|c|}{ Emotional satisfaction } \\
\hline CHEM & 62.89 & 63.52 & 0.747 & 0.04 \\
\hline $\mathrm{BIO}$ & 70.88 & 63.86 & $<.001$ & -0.41 \\
\hline MATH & 62.42 & 63.75 & 0.560 & 0.06 \\
\hline Fall 2020 & Presemester & Postsemester & p-value & $\begin{array}{l}\text { Effect } \\
\text { size }\end{array}$ \\
\hline \multicolumn{5}{|l|}{$\begin{array}{l}\text { Intellectual } \\
\text { accessibility }\end{array}$} \\
\hline CHEM & 50.87 & 51.10 & 0.861 & 0.01 \\
\hline $\mathrm{BIO}$ & 57.37 & 60.53 & 0.031 & 0.17 \\
\hline MATH & 55.21 & 52.36 & 0.093 & -0.13 \\
\hline \multicolumn{5}{|c|}{ Emotional satisfaction } \\
\hline CHEM & 62.78 & 62.91 & 0.922 & 0.01 \\
\hline $\mathrm{BIO}$ & 66.04 & 66.54 & 0.736 & 0.03 \\
\hline MATH & 64.99 & 61.70 & 0.056 & -0.15 \\
\hline
\end{tabular}

Comparing the survey results from the Spring, 2019, and Fall, 2019, semesters we find students feel all three subjects are more emotionally satisfying than intellectually accessible (Table 3). In addition, these attitudes are fairly stable. Over the course of a semester we measure little to no change in intellectual accessibility or emotional satisfaction with respect to chemistry, biology, and math. The one exception is a small, but statistically significant, decrease in emotional satisfaction with respect to biology during the Spring, 2019, semester, although the high SRMR value and low response rate for the postsemester survey suggests that this result may be an artifact. Furthermore, we note that biology seems to be more intellectually accessible and emotionally satisfying the either chemistry or math. This is consistent with anecdote that biology is easier than either math or chemistry and helps explain why biology is a more popular major at this school. 
Finally, it is interesting to try to compare these results with attitude scores reported in the literature. A particularly interesting data point for comparison is work by Rocabado et al. comparing changes in attitude towards chemistry for Black female students in an organic chemistry course. In this work the researchers used the ASCI V3 to measure student attitudes towards chemistry in a flipped organic course and compared the attitude change for Black female students with all other students in the course to see if the intervention of a flipped course narrowed the attitude gap for Black female students. The reported means for the Intellectual accessibility and Emotional satisfaction subscales for the Black female students were 2.75 and 3.70 , respectively, near the start of the course and improved to 2.94 and 3.88 by the end of the course. Converting these means to percentages, for the purposes of comparison, these values are 39.3\% (Intellectual accessibility) and 52.8\% (Emotional satisfaction) for the start of the course and $42.0 \%$ (Intellectual accessibility) and 55.4\% (Emotional satisfaction) for the end of the course. For all other students in the course these values are $41.9 \%$ (Intellectual accessibility) and $57.4 \%$ (Emotional satisfaction) for the start of the course and $46.1 \%$ (Intellectual accessibility) and 59.6\%. While the different methodologies between that work and the work presented here mean that we need to be cautious about comparison, it is interesting that all three groups find chemistry more emotionally satisfying than intellectually accessible. Furthermore, what's perhaps very surprising is that, at least at first glance, the HSI students consistently find chemistry more intellectually accessible and emotionally satisfying than either the Black female students or all other students. However, this seems consistent with work showing that, after controlling for factors like standardized test scores and Pell status, HBCUs have similar or improved outcomes for Black students compared to primarily White institutions. ${ }^{54}$ Although we would really like to compare this data with student attitudes at other minority-serving institutions, such as HBCUs, we were unable to find any comparable data quantifying attitude in the literature.

While student attitudes are relatively stable over the course of a typical semester, what about during an atypical semester? In March 2020, the campus switched to emergency remote instruction because of the COVID-19 pandemic. Over the course of this semester there was a small increase in intellectual accessibility with respect to chemistry, as well as a small decrease in intellectual accessibility with respect to biology and a medium-sized decrease in emotional satisfaction with respect to biology. While the low response rate for the postsemester survey tell us that we should be very careful about overinterpreting the results, it is at least interesting that the attitudes towards chemistry and biology move in opposite directions and suggest that there might be an interesting reason to investigate how the biology and chemistry instructors approached the switch to emergency remote instruction. Furthermore, while the Fall, 2020, semester surveys, a semester delivered entirely remotely, show no change in attitude over the course of the semester, both the presemester and postsemester surveys show that the students found chemistry, biology, and math all more intellectually accessible, although there was no similar increase in emotional satisfaction. While this evidence only provides a single data point and should be taken with caution, given the many documented difficulties for many instructors and students with emergency remote teaching it is surprising that students would appear to find these subjects more intellectually accessible and merits further investigation. ${ }^{55-61}$

\section{Limitations}

There are a number of limitations to this study. The low response rates, particularly for the postsemester surveys, mean we may not be getting representative samples of students, particularly if high achieving or highly motivated students are more likely to complete the 
survey. Given the campus demographics it is reasonable to assume we are capturing a reasonable sample of Hispanic students, Asian students, and students who receive Pell grants, but we may be undersampling, or even completely missing, students who identify as African American, American Indian, or even White. This is compounded by not collecting demographic data of the survey respondents. In addition, while we invited approximately 40 students to be interviewed, only 9 responded and participated. While the survey responses were fairly similar among the students, and support the idea that these instruments are measuring attitude, 9 data points is small enough that we may be missing alternative interpretations.

Surveys were distributed to students in four chemistry courses with different enrollments, which means that the larger courses are likely dominating the results. While we have modified the Qualtrics survey to be able to disaggregate the survey results by course, for this work we have chosen to keep the results aggregated to avoid drawing or inferring any conclusions about specific instructors which may potentially be identifiable.

These surveys have only been distributed to students in chemistry courses. While we can assume these students are also taking math and biology courses, we can't draw conclusions about why there may be changes to attitudes with respect to chemistry, math, or biology without further study. In addition, we can't rule out the possibility that a student taking this survey in a chemistry course would treat it the same as if they took it in a biology or math course. Finally, it should be noted that these measurements are, at best, each a snapshot in time about a fairlynarrow construct. In the best of situations, these instruments can alert us to changes, but provide no information about what may have led to those changes. In other words, these instruments can help answer the question of what, but can't answer the question of why.

\section{Conclusions}

We have modified the ASCI to create three instruments that attempt to measure attitudes with respect to chemistry, biology, and math for a population of students a Hispanic Serving Institution. Quantitative and qualitative evidence show the instruments are reliable and support an interpretation that the instruments measure a cognitive aspect of attitude and an affective aspect of attitude. These surveys show that students generally find biology more intellectually accessible and emotionally satisfying than either chemistry or math, and find all three subjects more emotionally satisfying than intellectually stimulating.. Finally, the switch to remote instruction during March, 2020, in response to the COVID-19 pandemic, lead to measurable changes in student attitudes, with an increase in intellectual accessibility with respect to chemistry, and a decrease in both intellectual accessibility and emotional satisfaction with respect to biology. 


\section{Acknowledgements}

The authors gratefully acknowledge funding support from the National Science Foundation (Hispanic Serving Institution Building Capacity, award \#1832538). In addition, JC gratefully acknowledges support from the Howard Hughes Medical Institution (Inclusive Excellence in Science Education, award \#GT11066). 


\section{References}

1. Attitude organization and the attitude-behavior relationship. American Psychological Association: US, 1979; Vol. 37, pp 913-929.

2. Murchison, C., A handbook of social psychology, by W.C. Allee, Gordon W. Allport, Friedrich Alverdes [and others] edited by Carl Murchison. Clark university press; H. Milford, Oxford university press, 1935: Massachusetts, 1935.

3. Lindzey, G., Handbook of social psychology. Addison-Wesley: Cambridge, Mass, 1954.

4. Rosenberg, M. J., Attitude organization and change; an analysis of consistency among attitude components, by Milton J. Rosenberg [and others]. Yale University Press: New Haven, 1960.

5. Ajzen, I., The theory of planned behavior. Organizational Behavior and Human Decision Processes 1991, 50 (2), 179-211.

6. Ajzen, I. F. M., Understanding attitudes and predicting social behavior. Prentice-Hall: Englewood Cliffs, N.J., 1980.

7. Fishbein, M. A. I., Belief, Attitude, Intention and Behavior : an Introduction to Theory and Research. Addison-Wesley: 1975.

8. Madden, T. J.; Ellen, P. S.; Ajzen, I., A Comparison of the Theory of Planned Behavior and the Theory of Reasoned Action. Personality and Social Psychology Bulletin 1992, 18 (1), 39.

9. $\quad$ Reid, N.; Skryabina, E. A., Attitudes towards physics. Research in Science \& Technological Education 2002, 20 (1), 67-81.

10. Skryabina, E., Students' attitudes to learning physics at school and university levels in Scotland. University of Glasgow (United Kingdom): 2000.

11. Xu, X.; Lewis, J. E., Refinement of a Chemistry Attitude Measure for College Students. Journal of Chemical Education 2011, 88 (5), 561-568.

12. Eagly, A. H.; Chaiken, S., The Advantages of an Inclusive Definition of Attitude. Social Cognition 2007, 25 (5), 582-602.

13. An, J.; Poly, L.-P.; Holme, T. A., Usability Testing and the Development of an Augmented Reality Application for Laboratory Learning. Journal of Chemical Education 2020, 97 (1), 97-105.

14. Pazicni, S.; Flynn, A. B., Systems Thinking in Chemistry Education: Theoretical Challenges and Opportunities. Journal of Chemical Education 2019, 96 (12), 2752-2763.

15. Rocabado, G. A.; Kilpatrick, N. A.; Mooring, S. R.; Lewis, J. E., Can We Compare Attitude Scores among Diverse Populations? An Exploration of Measurement Invariance Testing to Support Valid Comparisons between Black Female Students and Their Peers in an Organic Chemistry Course. Journal of Chemical Education 2019, 96 (11), 2371-2382.

16. Hofstein, A., Science Education. 2017; p 357.

17. Brandriet, A. R.; Ward, R. M.; Bretz, S. L., Modeling meaningful learning in chemistry using structural equation modeling. Chemistry Education Research and Practice 2013, 14 (4), 421-430.

18. Villafañe, S. M.; Lewis, J. E., Exploring a Measure of Science Attitude for Different Groups of Students Enrolled in Introductory College Chemistry. Chem. Educ. Res. Pract. 2016, 17,731 .

19. Xu, X.; Villafañe, S. M.; Lewis, J. E., College Students' Attitudes Toward Chemistry, Conceptual Knowledge and Achievement: Structural Equation Model Analysis. Chem. Educ. Res. Pract. 2013, 14, 188. 
20. Chan, J. Y. K.; Bauer, C. F., Identifying At-Risk Students in General Chemistry via Cluster Analysis of Affective Characteristics. J. Chem. Educ. 2014, 91, 1417.

21. Pintrich, P. R.; De Groot, E. V., Motivational and Self-Regulated Learning Components of Classroom Academic Performance. J. Educ. Psychol. 1990, 82, 33.

22. Quinn, R., 2013.

23. Cahill, M. J.; McDaniel, M. A.; Frey, R. F.; Hynes, K. M.; Repice, M.; Zhao, J.; Trousil, R., Understanding the relationship between student attitudes and student learning. Physical Review Physics Education Research 2018, 14 (1), 010107.

24. Mooring, S. R.; Mitchell, C. E.; Burrows, N. L., Evaluation of a Flipped, LargeEnrollment Organic Chemistry Course on Student Attitude and Achievement. J. Chem. Educ. 2016, 93 (12), 1972.

25. Cracolice, M. S.; Busby, B. D., Preparation for College General Chemistry: More than Just a Matter of Content Knowledge Acquisition. Journal of Chemical Education 2015, 92 (11), $1790-1797$.

26. Gibbons, R. E.; Xu, X.; Villafañe, S. M.; Raker, J. R., Testing a Reciprocal Causation Model Between Anxiety, Enjoyment and Academic Performance in Postsecondary Organic Chemistry. Educational Psychology 2018, 38 (6), 838.

27. Hunter, A.-B.; Seymour, E., Talking about leaving revisited : persistence, relocation, and loss in undergraduate STEM education. Springer: Cham, Switzerland, 2019.

28. National Academies of Sciences, E.; Medicine, Undergraduate research experiences for STEM students: Successes, challenges, and opportunities. National Academies Press: 2017.

29. of Sciences, N. A.; of Engineering, N. A., Rising above the gathering storm, revisited: Rapidly approaching category 5. 2010.

30. Council, N. R., Discipline-Based Education Research: Understanding and Improving Learning in Undergraduate Science and Engineering. The National Academies Press: Washington, DC, 2012; p 282.

31. White, K. N.; Vincent-Layton, K.; Villarreal, B., Equitable and Inclusive Practices Designed to Reduce Equity Gaps in Undergraduate Chemistry Courses. Journal of Chemical Education 2021, 98 (2), 330-339.

32. Bancroft, S. F.; Fowler, S. R.; Jalaeian, M.; Patterson, K., Leveling the Field: Flipped Instruction as a Tool for Promoting Equity in General Chemistry. Journal of Chemical Education 2020, 97 (1), 36-47.

33. Fink, A.; Cahill, M. J.; McDaniel, M. A.; Hoffman, A.; Frey, R. F., Improving general chemistry performance through a growth mindset intervention: Selective effects on underrepresented minorities. Chemistry Education Research and Practice 2018, 19 (3), 783-806. 34. Lewis, S. E.; Lewis, J. E., Seeking effectiveness and equity in a large college chemistry course: an HLM investigation of Peer-Led Guided Inquiry. Journal of Research in Science Teaching 2008, 45 (7), 794-811.

35. Estrada, M.; Burnett, M.; Campbell, A. G.; Campbell, P. B.; Denetclaw, W. F.; Gutiérrez, C. G.; Hurtado, S.; John, G. H.; Matsui, J.; McGee, R., et al., Improving Underrepresented Minority Student Persistence in STEM. CBE-Life Sciences Education 2016, 15 (3), es5.

36. Kanim, S.; Cid, X. C., Demographics of physics education research. Physical Review Physics Education Research 2020, 16 (2), 020106.

37. Wilson-Kennedy, Z. S.; Payton-Stewart, F.; Winfield, L. L., Toward Intentional Diversity, Equity, and Respect in Chemistry Research and Practice. Journal of Chemical Education 2020, 97 (8), 2041-2044. 
38. National Academies of Sciences, E.; Medicine, Minority serving institutions: America's underutilized resource for strengthening the STEM workforce. National Academies Press: 2019. 39. Van Dusen, B.; Nissen, J., Associations between learning assistants, passing introductory physics, and equity: A quantitative critical race theory investigation. Physical Review Physics Education Research 2020, 16 (1), 010117.

40. $\quad$ Adams, W. K.; Wieman, C. E.; Perkins, K. K.; Barbera, J., Modifying and validating the Colorado Learning Attitudes about Science Survey for use in chemistry. J. Chem. Educ. 2008, 85 (10), 1435.

41. Bauer, C. F., Beyond "student attitudes": Chemistry self-concept inventory for assessment of the affective component of student learning. J. Chem. Educ. 2005, 82 (12), 1864. 42. Bauer, C. F., Attitude toward chemistry: a semantic differential instrument for assessing curriculum impacts. J. Chem. Educ. 2008, 85 (10), 1440.

43. Cooper, M. M.; Sandi-Urena, S., Design and validation of an instrument to assess metacognitive skillfulness in chemistry problem solving. J. Chem. Educ. 2009, 86 (2), 240.

44. Grove, N.; Bretz, S. L., CHEMX: An instrument to assess students' cognitive expectations for learning chemistry. J. Chem. Educ. 2007, 84 (9), 1524.

45. Liu, Y.; Ferrell, B.; Barbera, J.; Lewis, J. E., Development and evaluation of a chemistryspecific version of the academic motivation scale (AMS-Chemistry). Chem. Educ. Res. Pract. 2017, $18(1), 191$.

46. Wachsmuth, L. P.; Runyon, C. R.; Drake, J. M.; Dolan, E. L., Do Biology Students Really Hate Math? Empirical Insights into Undergraduate Life Science Majors' Emotions about Mathematics. CBE-Life Sciences Education 2017, 16 (3), ar49.

47. Chatterjee, S.; Williamson, V. M.; McCann, K.; Peck, M. L., Surveying students' attitudes and perceptions toward guided-inquiry and open-inquiry laboratories. J. Chem. Educ. 2009, $86(12), 1427$.

48. Lacosta-Gabari, I.; Fernández-Manzanal, R.; Sánchez-Gonzólez, D., Designing, Testing, and Validating an Attitudinal Survey on an Environmental Topic. A Groundwater Pollution Survey Instrument for Secondary School Students. Journal of Chemical Education 2009, 86 (9), 1099.

49. Walczak, D. E.; Walczak, M. M., Do Student Attitudes toward Science Change during a General Education Chemistry Course? Journal of Chemical Education 2009, 86 (8), 985.

50. Xu, X.; Alhoosani, K.; Southam, D.; Lewis, J. E., Affective Dimensions in Chemistry. 2015; p 177.

51. Montes, L. H.; Ferreira, R. A.; Rodriguez, C., Explaining Secondary School Students' Attitudes Towards Chemistry in Chile. Chem. Educ. Res. Pract. 2018, 19 (2), 533.

52. Cohen, J., Statistical Power Analysis for the Behavioral Sciences. 1988.

53. $\mathrm{Xu}, \mathrm{X}$. Refinement of a Chemistry Attitude Measure for College Students. University of South Florida, 2010.

54. Richards, D. A.; Awokoya, J. T., Understanding HBCU Retention and Completion. Frederick D. Patterson Research Institute, UNCF 2012.

55. Rupnow, R. L.; LaDue, N. D.; James, N. M.; Bergan-Roller, H. E., A Perturbed System: How Tenured Faculty Responded to the COVID-19 Shift to Remote Instruction. Journal of Chemical Education 2020, 97 (9), 2397-2407.

56. Perets, E. A.; Chabeda, D.; Gong, A. Z.; Huang, X.; Fung, T. S.; Ng, K. Y.; Bathgate, M.; Yan, E. C. Y., Impact of the Emergency Transition to Remote Teaching on Student Engagement 
in a Non-STEM Undergraduate Chemistry Course in the Time of COVID-19. Journal of Chemical Education 2020, 97 (9), 2439-2447.

57. Villanueva, O.; Behmke, D. A.; Morris, J. D.; Simmons, R.; Anfuso, C.; Woodbridge, C. M.; Guo, Y., Adapting to the COVID-19 Online Transition: Reflections in a General Chemistry Sequence Taught by Multiple Instructors with Diverse Pedagogies. Journal of Chemical Education 2020, 97 (9), 2458-2465.

58. Jeffery, K. A.; Bauer, C. F., Students' Responses to Emergency Remote Online Teaching Reveal Critical Factors for All Teaching. Journal of Chemical Education 2020, 97 (9), 24722485.

59. Petillion, R. J.; McNeil, W. S., Student Experiences of Emergency Remote Teaching: Impacts of Instructor Practice on Student Learning, Engagement, and Well-Being. Journal of Chemical Education 2020, 97 (9), 2486-2493.

60. E.Gin, L.; A.Guerrero, F.; E.Brownell, S.; M.Cooper, K., COVID-19 and Undergraduates with Disabilities: Challenges Resulting from the Rapid Transition to Online Course Delivery for Students with Disabilities in Undergraduate STEM at Large-Enrollment Institutions. CBE-Life Sciences Education 2021, 20 (3), ar36.

61. Walsh, L. L.; Arango-Caro, S.; Wester, E. R.; Callis-Duehl, K., Training Faculty as an Institutional Response to COVID-19 Emergency Remote Teaching Supported by Data. CBELife Sciences Education 2021, 20 (3), ar34. 